\title{
Opioid Use Disorder: Screening, Diagnosis, and Management
}

Privia Randhawa', Seonaid Nolan ${ }^{1,2}$

${ }^{1}$ British Columbia Centre on Substance Use, Vancouver, BC, Canada; ${ }^{2}$ Department of Medicine, University of British Columbia, St. Paul's Hospital, Vancouver, BC, Canada

Author for correspondence: Seonaid Nolan: Seonaid.nolan@bccsu.ubc.ca

Received: 13 February 2020; Accepted after revision: 27 April 2020; Published: 21 June 2021

DOI:https://doi.org/10.22374/cjgim.v16i2.425

\begin{abstract}
Over the past decade, the opioid crisis in Canada has been worsening. In 2019, over 3,800 people across Canada died due to an apparent opioid-related cause, which represents a $26 \%$ increase from just 3 years prior. Given North America's ongoing opioid crisis, and the contribution opioid-prescribing practices have had to date, a critical need exists to ensure that health care providers are not only educated about safe opioid prescribing but also are knowledgeable about how to effectively screen for, diagnose, and treat an individual with opioid use disorder.
\end{abstract}

\section{Résumé}

Au cours des dix dernières années, la crise des opioïdes au Canada n’a cessé de s'aggraver. En 2019, plus de 3800 personnes au Canada sont décédées d'une cause apparemment liée à la consommation d'opioïdes, ce qui représente une augmentation de $26 \%$ par rapport à seulement trois ans auparavant. Étant donné la crise des opioïdes qui sévit actuellement en Amérique du Nord et la contribution des pratiques de prescription d'opioïdes qui ont eu cours jusqu'ici, un besoin critique est à combler pour veiller à ce que les fournisseurs de soins soient non seulement formés sur la prescription sécuritaire des opioïdes, mais aussi bien informés sur le dépistage, le diagnostic et le traitement efficace d'un trouble lié à la consommation d’opioïdes.

\section{Introduction}

Canada is in the midst of an opioid crisis that has been progressively worsening. In 2019, over 3,800 Canadians died of an opioidrelated cause, which represents a $26 \%$ increase from just 3 years prior in 2016. ${ }^{1}$ Though British Columbia (BC) has been facing a disproportionate number of deaths per year, the opioid crisis is affecting communities from every province and territory across Canada, with similar trends being seen in the United States. ${ }^{2}$

While reasons for North America's recent increase in opioidrelated deaths are certainly multifactorial, opioid-prescribing practices related to the treatment of acute and/or chronic pain has previously been recognized as a significant contributor. ${ }^{3}$ Though Canadian data is lacking, prescription opioid misuse was found to be the second most common illicit drug used (after marijuana) in the previous month by surveyed Americans (aged 12 years or older) in $2018 .{ }^{4}$ Similarly, almost $20 \%$ of the 53 million Americans who reported past-year use of illicit drugs in 2018 reported the misuse of prescription opioids. ${ }^{4}$ While a significant proportion of individuals who misused prescription opioids did so to relieve physical pain (64\%), the second most common reason cited was to feel good or get high (11\%). Regarding the source of misused prescription opioids, approximately $51 \%$ were 
given by, bought from, or taken from a friend or relative, while $37 \%$ obtained opioids directly through a prescription. ${ }^{4}$

Canada is now the second highest global opioid consumer, after the United States, with rates of pharmaceutical opioid use having tripled over the past decade alone. ${ }^{5}$ For many years, prescribers have been faulted for oligoanesthesia-the undertreatment of acute pain. ${ }^{6,7}$ To ensure pain was not dismissed and instead treated sufficiently, there was a push for physicians to treat pain more aggressively. ${ }^{8}$ In addition, pharmaceutical companies employed forceful, and sometimes deceiving, marketing strategies to increase opioid sales. ${ }^{9,10}$ Together, these influences have contributed to steep increases in opioid prescriptions over the past decade, in every province across Canada. ${ }^{11}$ As recent evidence and guidelines are beginning to highlight, opioids have limited effectiveness in the treatment of chronic, noncancer pain. ${ }^{12}$ Moreover, the risks of opioid use likely outweigh their potential short-term benefits when used to treat mild to moderate acute pain. ${ }^{13}$

Beyond increased rates of opioid prescribing, there is also evidence of high-risk prescribing practices. BC data, for example, demonstrate that among patients being prescribed methadone maintenance treatment for an opioid use disorder, approximately $35 \%$ also received a concurrent prescription for an additional opioid between 1996 and 2006. ${ }^{14}$ Furthermore, the number of opioid prescriptions per person per year nearly doubled within the same timeframe. ${ }^{14}$ Looking at the source of concurrent opioid prescriptions, the vast majority $(74 \%)$ were prescribed to a patient by a physician that was not their methadone provider. ${ }^{14}$ Such a practice proves problematic as the co-prescription of opioids and methadone have important safety considerations as evidenced by the risk of fatal and nonfatal overdoses related to concurrent opioid use. ${ }^{15,16}$

While opioid-prescribing practices have undoubtedly contributed to North America's opioid crisis, the presence of fentanyl (and its potent analogues) in the illicit drug supply cannot be ignored. In 2019, 77\% of accidental, apparent opioid-related deaths in Canada involved fentanyl or one of its analogues compared to only $54 \%$ of apparent opioid-related deaths in $2016 .{ }^{1,17}$ The use of nonmedical prescription opioids, however, has previously been identified to be a risk factor for subsequent illicit opioid use (with some studies citing up to a 40 -fold increased risk for the development of a heroin use disorder among those with a nonmedical prescription opioid use disorder compared to those without). ${ }^{18-24}$ More specifically, a 2013 national US study demonstrated that among individuals with both nonmedical prescription opioid use and heroin use in the preceding year, $77 \%$ reported their heroin use was concerned with nonmedical prescription opioids. ${ }^{25}$ Accordingly, given North America's ongoing opioid crisis and the contribution opioid-prescribing practices have had to date, a critical need exists to ensure health care providers are not only educated about safe opioid prescribing but also are knowledgeable about how to effectively screen for, diagnose, and treat an individual with opioid use disorder.

\section{Opioid Use Disorder: Screening and Diagnosis}

Historically, there has been a lack of focus on pain management or addiction medicine training in medical education (both in Canada and the United States). Accordingly, screening patients for either substance misuse or addiction is not routinely integrated into many clinician's existing workflows. Though Canadian data are lacking, one national survey of primary care physicians in the United States demonstrated $94 \%$ of respondents $(n=648)$ reported being unable to identify a substance use disorder among their adult patients. ${ }^{26}$ Accordingly, being able to accurately screen for and diagnose opioid use disorder is of critical importance.

The Rapid Opioid Dependence Screen (RODS) is an eightitem survey that can provide targeted screening for opioid dependence (as defined by the Diagnostic and Statistical Manual of Mental Disorders [DSM], Fourth Edition) in either a clinical or research setting. ${ }^{27}$ The instrument, on average, takes less than 2 minutes to administer and can be done individually or as part of a more thorough assessment. The RODS has demonstrated good-to-strong sensitivity (97\%) and specificity (76\%), among newly incarcerated HIV-infected individuals. ${ }^{27}$ An individual screens "positive" if they respond "yes" to at least three questions. A "positive" screen should then be followed up with a formal diagnosis of opioid use disorder using the 11-item criteria from the DSM-Fifth Edition. The severity of opioid use disorder can further be classified as mild (score: 2-3), moderate (score: $4-5$ ), or severe (score $\geq 6$ ). Additional screening tools have been validated in various populations, for example, the Mini International Neuropsychiatric Interview (MINI) and the National Institute on Drug Abuse Modified Alcohol, Smoking, and Substance Involvement Screening Test (NMASSIST). ${ }^{28}$ As each screening/ diagnostic tool has specific benefits and drawbacks in relation to reliability, validity, and time of administration, it is important to carefully consider the most appropriate choice dependent on the population at hand. Most importantly, any individual diagnosed with an opioid use disorder should be offered and initiated on evidence-based treatment in a timely fashion by either the patient's primary care provider or referral to a practitioner with expertise in addiction medicine.

\section{Opioid Use Disorder: Management}

In the spring of 2018, a national Canadian guideline for the treatment of opioid use disorder was published. ${ }^{29}$ The guideline describes the need for the treatment of opioid use disorder to occur along a continuum, with treatment intensity matched 
to disease severity. Furthermore, a need exists for ongoing reassessment to ensure a patient's treatment needs (which may evolve over time) are consistently being met. Harm reduction strategies (e.g., take-home naloxone kits, safe injection, or overdose prevention education) and/or psychosocial interventions (e.g., counselling, group therapy, residential treatment) should span the entire treatment continuum and be offered to all patients as standard practice.

\section{Withdrawal management}

Withdrawal management (e.g., detox) is considered merely symptom management in the realm of treatment modalities for opioid use disorder and, therefore, should not be used as a treatment option without additional support. Methadone and buprenorphine/naloxone can be used as a taper to reduce symptoms of opioid withdrawal, albeit with certain risks. ${ }^{30}$ For example, many patients did not complete treatment and there were high rates of relapse during and after tapers, which results in the potential of overdoses and deaths. ${ }^{30,31}$

In addition, although alpha ${ }_{2}$-adrenergic agonists (e.g., clonidine) tend to relieve opioid withdrawal symptoms faster than a methadone taper and usually require a shorter length of treatment, they may also be associated with certain side effects including sedation, dry mouth, and/or hypotension. ${ }^{32}$ Conversely, buprenorphine/naloxone provides more rapid symptom relief for opioid withdrawal and its use is associated with higher rates of withdrawal management completion when compared to a methadone taper. ${ }^{19}$ Furthermore, compared to alpha 2 -adrenergic agonists, buprenorphine/naloxone is more effective at relieving opioid withdrawal symtpoms. ${ }^{33}$ Regardless of which medication is used, it is important to note that withdrawal management should never be offered in isolation (e.g., without transition to ongoing maintenance therapy) as such an approach is associated with higher rates of relapse, ${ }^{21} \mathrm{HIV}$ infection and transmission, ${ }^{20}$ and increased morbidity and mortality. ${ }^{34}$ In addition, pairing psychosocial interventions with medical management appears to be a helpful adjunct in the context of opioid withdrawal management. ${ }^{35}$

\section{Opioid agonist therapy}

First-line treatment for opioid use disorder is opioid agonist therapy. Given its improved safety profile (and decreased risk for diversion), buprenorphine/naloxone is currently recommended as first-line therapy for opioid use disorder treatment. Buprenorphine is a partial opioid agonist, and confers a lower risk for sedation and respiratory depression, as well as a sixfold decreased risk for overdose when compared to methadone. ${ }^{36,37}$ Furthermore, the medication has few drug-drug interactions and is not associated with prolongation of the cardiac QT interval. ${ }^{37}$
Compared to placebo, buprenorphine/naloxone is associated with increased rates of treatment retention (buprenorphine daily dose $>2$ milligrams [mg]) and suppression in illicit opioid use (buprenorphine daily dose $\geq 16 \mathrm{mg}$ ). ${ }^{38}$ Therapeutic dosing of buprenorphine/naloxone can be achieved within 24-72 h, and given its safety profile, the medication can be prescribed for take-home dosing earlier than methadone. Moderate to severe withdrawal from full opioid agonists (either prescribed or illicit) must be achieved for a period of time prior to induction to prevent the occurrence of precipitated withdrawal. While more novel induction techniques (e.g., the Bernese method of buprenorphine/naloxone microdosing) can be successful without the need for the patient to experience opioid withdrawal, such an approach is currently off-label. ${ }^{39}$ Specific details regarding how to prescribe buprenorphine/naloxone for opioid use disorder treatment can be found in province-specific guidelines. ${ }^{12,40-42}$

Methadone, a full opioid agonist, has been available as a treatment option for opioid use disorder since 1965. Accordingly, its efficacy is supported by a large body of literature, spanning various countries, jurisdictions, and socioeconomic settings. ${ }^{43,44}$ Compared to placebo, methadone maintenance therapy has been shown to be significantly more effective in addiction treatment retention, suppression of illicit opioid use,${ }^{43}$ reduction in mortality (2.6 versus 12.7 per 1000 person years) ${ }^{45}$ and reduction in HIV infection. ${ }^{46}$ When buprenorphine/naloxone and methadone are compared, both medications (when prescribed at medium or high doses [ $\geq 7 \mathrm{mg}$ daily buprenorphine/naloxone, $\geq 40 \mathrm{mg}$ daily methadone]) have proven equally efficacious for retention in addiction treatment and reduction in illicit opioid use. ${ }^{38}$ Given the prolonged half-life of methadone, dose adjustments are currently recommended every 3 to 7 days (depending on specific provincial guidelines and risk of patient methadone toxicity). ${ }^{12,47}$ Accordingly, it can take weeks or even months to achieve a therapeutic dose. During this period, it is not uncommon for patients to discontinue treatment, experience adverse events, or overdose. ${ }^{48}$ Specific details regarding how to prescribe methadone for opioid use disorder treatment can be found in province-specific guidelines. ${ }^{12,40,49-53}$

\section{Novel and emerging treatments}

Slow-release oral morphine (SROM) is a 24 -h, extended release formulation of morphine that can be prescribed as an alternative treatment option to either methadone and/or buprenorphine/ naloxone for opioid use disorder. Although a 2013 Cochrane review did not show conclusive results in treatment retention or effectiveness of SROM, it is important to note that only three studies were available at the time and thus included in the review. ${ }^{54,55}$ Since then, data have emerged demonstrating the efficacy of SROM (when compared to methadone) with regard 
to similar rates of addiction treatment retention, ${ }^{56}$ a reduction in illicit opioid use and cravings, ${ }^{55}$ as well as no interaction with the cardiac QTc interval. ${ }^{56}$ If buprenorphine/naloxone or methadone is unsuccessful or contraindicated for the treatment of opioid use disorder, SROM should be considered. Of note, a portion of the studies investigating SROM have been uncontrolled, pointing to a need for more robust trials. Therefore, SROM is not recommended as a first-line treatment option for opioid use disorder. Health care providers should seek expert consultation from an addiction medicine specialist prior to prescribing. ${ }^{12,57}$

Injectable opioid agonist therapy (iOAT), such as diacetylmorphine (DAM), the active ingredient in heroin, has been offered as a treatment for severe opioid use disorder in several European settings for decades. ${ }^{58,59}$ Individuals who have experienced treatment failure with oral opioid agonist therapy (e.g., buprenorphine/naloxone, methadone, SROM) may be considered for treatment with iOAT, which has demonstrated efficacy in improving addiction treatment retention, reducing illicit opioid and stimulant use, ensuring decreased criminal activity, and improving social functioning. ${ }^{60}$ In Canada, injectable DAM is currently only available through the federal Special Access Program, which greatly limits its availability as a treatment option. ${ }^{60}$ In 2015, injectable hydromorphone was found to be noninferior to injectable DAM in a Vancouver-based randomized controlled trial. ${ }^{41}$ Subsequent to this, injectable hydromorphone was approved as a treatment option for severe opioid use disorder among Canadian adults in the spring of 2019. A few months later, Canada adopted national iOAT guidelines for the treatment of opioid use disorder. ${ }^{61}$ Of note, however, prescribing of iOAT for the treatment of opioid use disorder is limited to health care providers with appropriate training and expertise.

\section{Antagonist therapies}

Naltrexone is an opioid antagonist that binds to opioid receptors and blocks the effects of other opioid agonists. Oral naltrexone has been evaluated as a treatment option for opioid use disorder, but compared to placebo or no treatment, the medication demonstrated no significant difference in treatment retention or abstinence rates in a 2011 meta-analysis. ${ }^{62}$ Compared to its oral counterpart, extended-release naltrexone has been shown to increase adherence to therapy, partially attributed to its intramuscular route of administration. ${ }^{63}$ In addition to decreased opioid cravings when compared to methadone, patients who use extended-release naltrexone for OUD have improved treatment retention and reduced illicit opioid use overall, when compared to placebo. ${ }^{64}$ In contrast to the United States, extended-release naltrexone is not available to Canadians unless it is approved through Health Canada on a case-by-case basis. In addition to the hurdle of availability, patients are required to pay for it, as it does not fall under provincial medical coverage.

\section{Conclusion}

Over the past decade, the opioid-related death toll has continued to increase, prompting a public health emergency in both Canada and the United States. Though reasons for the current opioid crisis are multifactorial, health care providers' opioid-prescribing practices and the prevalence of fentanyl and other potent analogues in the illicit drug supply have been highlighted as significant contributors. Moving forward, if we are ever to turn the tide on the opioid epidemic a critical need exists to ensure health care providers are not only educated about safe opioid prescribing but also are knowledgeable about how to effectively screen for, diagnose, and treat an individual with opioid use disorder. Furthermore, opioid agonist treatment (e.g., buprenorphine/naloxone, methadone) should be routinely offered to any patient identified to have an opioid use disorder to prevent the negative consequences associated with ongoing use.

\section{References}

1. Special Advisory Committee on the Epidemic of Opioid Overdoses. Opioidrelated harms in Canada [Internet]. 2020. Available from: https://healthinfobase.canada.ca/substance-related-harms/opioids

2. Centers for Disease Control and Prevention. 2019 Annual surveillance report of drug-related risks and outcomes-United States surveillance special report. Centers for Disease Control and Prevention, US Department of Health and Human Services.

3. Wright ER, Kooreman HE, Greene MS, Chambers RA, Banerjee A, Wilson J. The iatrogenic epidemic of prescription drug abuse: Countylevel determinants of opioid availability and abuse. Drug Alcohol Depend. 2014;138:209-15. http://dx.doi.org/10.1016/j.drugalcdep.2014.03.002

4. Substance Abuse and Mental Health Services Administration. Key substance use and mental health indicators in the United States: Results from the 2018 National Survey on Drug Use and Health. (HHS Publication No PEP19-5068, NSDUH Series H-54).

5. International Narcotics Control Board. Availability of narcotic drugs for medical use [Internet]. 2019. Available from: https://www.incb.org/incb/en/ narcotic-drugs/Availability/availability.html

6. Reichl M, Bodiwala GG. Use of analgesia in severe pain in the accident and emergency department. Arch Emerg Med. 1987;4(1):25-31. http://dx.doi. org/10.1136/emj.4.1.25

7. Wilson JE, Pendleton JM. Oligoanalgesia in the emergency department. Am J Emerg Med. 1989;7(6):620-3. http://dx.doi. org/10.1016/0735-6757(89)90286-6

8. Hoffman J, Tavernise S. Vexing question on patient surveys: Did we ease your pain? [Internet]. New York Times. 2016 [cited 2019]. Available from: https:// www.nytimes.com/2016/08/05/health/pain-treatment-hospitals-emergencyrooms-surveys.html?_r=0

9. Fischer B, Keates A, Buhringer G, Reimer J, Rehm J. Non-medical use of prescription opioids and prescription opioid-related harms: Why so markedly higher in North America compared to the rest of the world? Addiction. 2014;109(2):177-81. http://dx.doi.org/10.1111/add.12224

10. Fischer B, Rehm J, Tyndall M. Effective Canadian policy to reduce harms from prescription opioids: Learning from past failures. CMAJ. 2016;188(1718):1240-4. http://dx.doi.org/10.1503/cmaj.160356 
11. Fischer B, Jones W, Rehm J. Trends and changes in prescription opioid analgesic dispensing in Canada 2005-2012: An update with a focus on recent interventions. BMC Health Serv Res. 2014;14:90. http://dx.doi. org/10.1186/1472-6963-14-90

12. British Columbia Centre on Substance Use and B.C. Ministry of Health. A guideline for the clinical management of opioid use disorder. 2017 [cited 2018 Nov 14]

13. Dunn KM, Saunders KW, Rutter CM, et al. Opioid prescriptions for chronic pain and overdose: A cohort study. Ann Intern Med. 2010;152(2):85-92. http://dx.doi.org/10.7326/0003-4819-152-2-201001190-00006

14. Nosyk B, Fischer B, Sun H, et al. High levels of opioid analgesic coprescription among methadone maintenance treatment clients in British Columbia, Canada: Results from a population-level retrospective cohort study. Am J Addict. 2014;23(3):257-64. http://dx.doi. org/10.1111/j.1521-0391.2014.12091.x

15. Cornish R, Macleod J, Strang J, Vickerman P, Hickman M. Risk of death during and after opiate substitution treatment in primary care: Prospective observational study in UK General Practice Research Database. BMJ (Clinical research ed). 2010;341:c5475. http://dx.doi.org/10.1136/bmj.c5475

16. Marteau D, McDonald R, Patel K. The relative risk of fatal poisoning by methadone or buprenorphine within the wider population of England and Wales. BMJ Open. 2015;5(5):e007629.

17. Special Advisory Committee on the Epidemic of Opioid Overdoses. Opioidrelated harms in Canada.

18. Grau LE, Dasgupta N, Grau LE, et al. Illicit use of opioids: Is OxyContin ${ }^{\circ}$ a "gateway drug"? Am J Addict. 2007;16(3):166-73. http://dx.doi. org/10.1080/10550490701375293

19. Lankenau SE, Teti M, Silva K, Bloom JJ, Harocopos A, Treese M. Initiation into prescription opioid misuse amongst young injection drug users. Int J Drug Policy. 2012;23(1):37-44. http://dx.doi.org/10.1016/j. drugpo.2011.05.014

20. Pollini RA, Banta-Green CJ, Cuevas-Mota J, Metzner M, Teshale E, Garfein RS. Problematic use of prescription-type opioids prior to heroin use among young heroin injectors. Subst Abuse Rehabil. 2011;2:173. http://dx.doi. org/10.2147/SAR.S24800

21. Mars SG, Bourgois P, Karandinos G, Montero F, Ciccarone D. "Every 'never' I ever said came true": Transitions from opioid pills to heroin injecting. Int J Drug Policy. 2014;25(2):257-66. http://dx.doi.org/10.1016/j. drugpo.2013.10.004

22. Cicero TJ, Ellis MS, Surratt HL, Kurtz SP. The changing face of heroin use in the United States: A retrospective analysis of the past 50 years. JAMA Psychiatry. 2014;71(7):821-6. http://dx.doi.org/10.1001/ jamapsychiatry.2014.366

23. Jones CM, Logan J, Gladden RM, Bohm MK. Vital signs: Demographic and substance use trends among heroin users-United States, 2002-2013. MMWR Morb Mortal Wkly Rep. 2015;64(26):719.

24. Muhuri P, Gfroerer J, Davies C. Associations of nonmedical pain reliever use and initiation of heroin use in the United States. CBHSQ Data Review. Substance Abuse and Mental Health Services Administration; 2013.

25. Jones $\mathrm{CM}$. Heroin use and heroin use risk behaviors among nonmedical users of prescription opioid pain relievers-United States, 2002-2004 and 2008-2010. Drug Alcoh Depend. 2013;132(1-2):95-100. http://dx.doi. org/10.1016/j.drugalcdep.2013.01.007

26. Macy J, Jr. Foundation, University of Illinois at Chicago. College of Urban Planning and Public Affairs. Survey Research Laboratory, Columbia University. National Center on Addiction and Substance Abuse. Missed opportunity: CASA National survey of primary care physicians and patients on substance abuse. National Center on Addiction and Substance Abuse at Columbia University; 2000.

27. Wickersham JA, Azar MM, Cannon CM, Altice FL, Springer SA. Validation of a brief measure of opioid dependence: The rapid opioid dependence screen (RODS). J Correct Health Care. 2015;21(1):12-26. http://dx.doi. org/10.1177/1078345814557513
28. Lindley B, Cox N, Cochran G. Screening tools for detecting problematic opioid use and potential application to community pharmacy practice: A review. Integr Pharm Res Pract. 2019;8:85-96. http://dx.doi.org/10.2147/ IPRP.S185663

29. Bruneau J, Ahamad K, Goyer ME, et al. Management of opioid use disorders: A national clinical practice guideline. CMAJ. 2018;190(9):E247-57. http:// dx.doi.org/10.1503/cmaj.170958

30. Amato L, Davoli M, Minozzi S, Ferroni E, Ali R, Ferri M. Methadone at tapered doses for the management of opioid withdrawal. Cochrane Database Syst Rev. 2013;(2):Cd003409. http://dx.doi.org/10.1002/14651858.CD003409. pub4

31. Fiellin DA, Schottenfeld RS, Cutter CJ, Moore BA, Barry DT, O'Connor PG. Primary care-based buprenorphine taper vs maintenance therapy for prescription opioid dependence: A randomized clinical trial. JAMA Intern Med. 2014;174(12):1947-54. http://dx.doi.org/10.1001/ jamainternmed.2014.5302

32. Gowing L, Farrell M, Ali R, White JM. Alpha(2)-adrenergic agonists for the management of opioid withdrawal. Cochrane Database Syst Rev. 2016;(5):Cd002024. http://dx.doi.org/10.1002/14651858.CD002024.pub5

33. Gowing L, Ali R, White JM. Buprenorphine for the management of opioid withdrawal. Cochrane Database Syst Rev. 2009;(3):CD002025. http://dx.doi. org/10.1002/14651858.CD002025.pub4

34. Strang J, McCambridge J, Best D, et al. Loss of tolerance and overdose mortality after inpatient opiate detoxification: Follow up study. BMJ. 2003;326(7396):959-60. http://dx.doi.org/10.1136/bmj.326.7396.959

35. Amato L, Minozzi S, Davoli M, Vecchi S. Psychosocial and pharmacological treatments versus pharmacological treatments for opioid detoxification. Cochrane Database Syst Rev. 2011;(9):Cd005031. http://dx.doi. org/10.1002/14651858.CD005031.pub4

36. Connery HS. Medication-assisted treatment of opioid use disorder: Review of the evidence and future directions. Harv Rev Psychiatr. 2015;23(2):63-75. http://dx.doi.org/10.1097/HRP.0000000000000075

37. Thomas CP, Fullerton CA, Kim M, et al. Medication-assisted treatment with buprenorphine: Assessing the evidence. Psychiatr Serv. 2014;65(2):158-70. http://dx.doi.org/10.1176/appi.ps.201300256

38. Mattick RP, Breen C, Kimber J, Davoli M. Buprenorphine maintenance versus placebo or methadone maintenance for opioid dependence. Cochrane Database Syst Rev. 2014;(2):Cd002207. http://dx.doi.org/10.1002/14651858. CD002207.pub4

39. Hammig R, Kemter A, Strasser J, et al. Use of microdoses for induction of buprenorphine treatment with overlapping full opioid agonist use: The Bernese method. Subst Abuse Rehabil. 2016;7:99-105. http://dx.doi. org/10.2147/SAR.S109919

40. College Pharmacists of Manitoba. Opioid agonist therapy guidelines for manitoba pharmacists. 2019.

41. Du Collège des Médecins du Québec et de l’Ordre des Pharmaciens du Québec. La buprénorphine dans le traitement de la dépendance aux opioïdes. 2009.

42. Centre for Addiction and Mental Health. Buprenorphine/nalaxone for opioid sependence: Clinical practice guideline. 2012.

43. Mattick RP, Breen C, Kimber J, Davoli M. Methadone maintenance therapy versus no opioid replacement therapy for opioid dependence. Cochrane Database Syst Rev. 2009;(3):Cd002209. http://dx.doi.org/10.1002/14651858. CD002209.pub2

44. Amato L, Davoli M, Perucci CA, Ferri M, Faggiano F, Mattick RP. An overview of systematic reviews of the effectiveness of opiate maintenance therapies: Available evidence to inform clinical practice and research. J Subst Abuse Treat. 2005;28(4):321-9. http://dx.doi.org/10.1016/j.jsat.2005.02.007

45. Sordo L, Barrio G, Bravo MJ, et al. Mortality risk during and after opioid substitution treatment: Systematic review and meta-analysis of cohort studies. BMJ. 2017;357:j1550. http://dx.doi.org/10.1136/bmj.j1550

46. Ahamad K, Hayashi K, Nguyen P, et al. Effect of low-threshold methadone maintenance therapy for people who inject drugs on HIV incidence in 


\section{Opioid use disorder}

Vancouver, BC, Canada: An observational cohort study. Lancet HIV. 2015;2(10):e445-50. http://dx.doi.org/10.1016/S2352-3018(15)00129-0

47. Program SM. Methadone guidelines and standards for the treatment of opioid addiction/dependence. 2015.

48. Socias ME, Wood E, Kerr T, et al. Trends in engagement in the cascade of care for opioid use disorder, Vancouver, Canada, 2006-2016. Drug Alcohol Depend. 2018;189:90-5. http://dx.doi.org/10.1016/j.drugalcdep.2018.04.026

49. College of Physicians and Surgeons of Alberta. Alberta methadone maintenance treatment standards and guidelines for dependence. 2014.

50. College of Physicians and Surgeons of Saskatchewan. Methadone guidelines and standards for the treatment of opioid addiction/dependence. 2015.

51. College of Physicians and Surgeons of Ontario. Methadone maintenance treatment program standards and clinical guidelines. 2011.

52. Newfoundlans and Labrador Pharmacy Board. Standards for the safe and effective provision of medication for the treatment of opioid dependence. 2015.

53. Nova Scotia College of Pharmacists. Standards of practice: Opioid agonist mainenance treatment services. 2017.

54. Ferri M, Minozzi S, Bo A, Amato L. Slow-release oral morphine as maintenance therapy for opioid dependence. Cochrane Database Syst Rev. 2013;(6):CD009879. http://dx.doi.org/10.1002/14651858.CD009879.pub2

55. Jegu J, Gallini A, Soler P, Montastruc JL, Lapeyre-Mestre M. Slowrelease oral morphine for opioid maintenance treatment: A systematic review. Br J Clin Pharmacol. 2011;71(6):832-43. http://dx.doi. org/10.1111/j.1365-2125.2011.03923.x

56. Hämmig R, Köhler W, Bonorden-Kleij K, et al. Safety and tolerability of slow-release oral morphine versus methadone in the treatment of opioid dependence. J Subst Abuse Treat. 2014;47(4):275-81. http://dx.doi. org/10.1016/j.jsat.2014.05.012
57. Canadian Institutes of Health Research. CRISM National Guideline for the Clinical Management of Opioid Use Disorder. 2018.

58. Verthein U, Bonorden-Kleij K, Degkwitz P, et al. Long-term effects of heroinassisted treatment in Germany. Addiction. 2008;103(6):960-6. http://dx.doi. org/10.1111/j.1360-0443.2008.02185.x

59. Güttinger F, Gschwend P, Schulte B, Rehm J, Uchtenhagen A. Evaluating long-term effects of heroin-assisted treatment: The results of a 6-year follow-up. European Addict Res. 2003;9(2):73-9. http://dx.doi. org/10.1159/000068811

60. Oviedo-Joekes E, Brissette S, Marsh DC, et al. Diacetylmorphine versus methadone for the treatment of opioid addiction. N Engl J Med. 2009;361(8):777-86. http://dx.doi.org/10.1056/NEJMoa0810635

61. Fairbairn N, Ross J, Trew M, et al. Injectable opioid agonist treatment for opioid use disorder: A national clinical guideline. CMAJ. 2019;191(38):E1049-56. http://dx.doi.org/10.1503/cmaj.190344

62. Minozzi S, Amato L, Vecchi S, Davoli M, Kirchmayer U, Verster A. Oral naltrexone maintenance treatment for opioid dependence. Cochrane Database Syst Rev. 2011;(4):Cd001333. http://dx.doi.org/10.1002/14651858. CD001333.pub3

63. Sullivan MA, Bisaga A, Mariani JJ, et al. Naltrexone treatment for opioid dependence: Does its effectiveness depend on testing the blockade? Drug Alcohol Depend. 2013;133(1):80-5. http://dx.doi.org/10.1016/j. drugalcdep.2013.05.030

64. Krupitsky E, Nunes EV, Ling W, Illeperuma A, Gastfriend DR, Silverman BL. Injectable extended-release naltrexone for opioid dependence: A double-blind, placebo-controlled, multicentre randomised trial. Lancet. 2011;377(9776):1506-13. http://dx.doi.org/10.1016/S0140-6736(11)60358-9 